\title{
PENEGAKAN DIAGNOSA KEPERAWATAN YANG SESUAI STANDAR
}

\author{
Niken Malinda Putri \\ nikenmalindaputri01@ gmail.com
}

\section{LATAR BELAKANG}

Pelayanan keperawatan merupakan Pelayanan profesional, sebagai bagian integral dari pelayanan kesehatan yang mempunyai daya ungkit besar terhadap pembangunan bidang kesehatan. Kualitas pelayanan kesehatan ditentukan salah satunya dari kualitas pelayanan keperawatan yang diberikan oleh perawat yang berkualitas (PPNI, 2016). Standar praktek keperawatan Undang-Undang No 38 Tahun 2014 dan peraturan tentang kewewenang praktek perawat oleh kepmenkes RI no 1239 tahun 2001 dan permenkes RI No 148 tahun 2010 yaitu kinerja perawat ditinjau dari pelaksanaan asuhan keperawatan yang meliputi pengkajian, diagnosa, intervensi, implentasi dan evaluasi. Dokumentasi yang efektif menjamin kesinambungan pelayanan, menghemat waktu, dan meminimalisasi resiko. Namun kenyataan nya masih banyak ditemukan ketidaksesuaian dokumentasi yang dilakukan oleh perawat. Pada prakteknya kegiatan proses keperawatan tidaklah selalu berurutan tetapi bisa dikerjakan pada waktu bersamaan/tumpang tindih (overlapping). Pengalaman menunjukkan bahwa sering sekali perawat kesulitan dalam menentukan diagnosa karena pengkajian yang dilakukan oleh perawat tidak mempunyai urutan yang efektif dan terstruktur (Nurjannah, I. 2012.).

Inti pokok yang akan dibahas adalah diagnosa keperawatan. Salah satu kegiatan yang penting dalam proses keperawatan adalah pengkajian keperawatan. Pengalaman menunjukkan bahwa sering sekali perawat kesulitan dalam menentukan diagnosis keperawatan spesifik yang dialami oleh pasien.Hal ini mungkin karena pengkajian keperawatan yang tidak terstruktur dengan baik. Penegakan diagnosis merupakan aspek penting dalam praktik keperawatan. Sepanjang waktu, format dan kualitas penegakan diagnosis telah berkembang, tetapi fokusnya terus berdampak terhadap perawatan klien (Potter \& Perry; 2009). Sistem penegakan diagnosis yang ideal harus memberikan informasi klien yang komprehensif, menunjukkan hasil dan standar klien, memfasilitasi reimbursement dari pemerintah dan dari perusahaan asuransi pembayar, serta berfungsi sebagai dokumen legal (Twardon dan Gartner, 1993: Potter \& Perry; 2009). Mutu asuhan keperawatan dapat tergambar dari penegakan diagnosis proses keperawatan (Gillies, 1994). 
Penegakan diagnosis dalam keperawatan memegang peranan penting terhadap segala macam tuntutan masyarakat yang semakin kritis dan mempengaruhi kesadaran masyarakat akan hak-haknya dari suatu unit kesehatan. Pendokumentasian yang tidak dilakukan dengan lengkap dapat menurunkan mutu pelayanan keperawatan karena tidak dapat mengidentifikasi sejauh mana tingkat keberhasilan asuhan keperawatan yang telah diberikan dalam aspek legal perawat tidak mempunyai bukti tertulis jika klien menuntut ketidakpuasan akan pelayanan keperawatan (Nursalam, 2008; Iyer, 2001).

Karena diagnosa dalam keperawatan memegang peranan penting maka diagnosa keperawatan harus dibuat dengan standarnya untuk mempermudah dalam pengkajian dan penegakkan diagnosa keperawatan, menegakkan diagnosa keperawatan sesuai standar yang mengacu kepada NANDA dan SDKI.

\section{METODE}

Metode yang saya gunakan dalam membuat kajian ini adalah metode literasi. Saya membaca berbagai literature maupun referensi dari jurnal, buku, koran, majalah maupun buku elektronik. Dengan metode literature ini saya dapat mengetahui peranan penting dari diagnosa keperawatan serta hal-hal yang mempengaruhi pembuatan diagnosa yang baik dan sesuai dengan standarnya.

\section{HASIL}

Hasil dari literature yang saya baca saya dapat mengetahui bahwa standar penegakan diagnosa keperawatan mengacu pada NANDA (North American Nursing Diagnosis Association) yang merupakan organisasi profesional perawat standar keperawatan terminologi dan Standar Diagnosa Keperawatan Indonesia (SDKI).

Pendokumentasian yang tidak dilakukan dengan lengkap dapat menurunkan mutu pelayanan keperawatan karena tidak dapat mengidentifikasi sejauh mana tingkat keberhasilan asuhan keperawatan yang telah diberikan dalam aspek legal perawat tidak mempunyai bukti tertulis jika klien menuntut ketidakpuasan akan pelayanan keperawatan.

Saya mengetahui bahwa Pada prakteknya kegiatan proses keperawatan tidaklah selalu berurutan tetapi bisa dikerjakan pada waktu bersamaan/tumpang tindih (overlapping).

Untuk melakukan diagnosa keperawatan yang baik dibutuhkan pengalaman untuk mencapai kualitas perawat professional. Perawat professional dalam mendokumentasikan 
diagnosis keperawatan harus memenuhi aspek pengetahuan, aspek efektif dan psikomotor juga harus mempunyai etika dalam legalitas dokumentasi keperawatan.

Dalam literature yang saya baca sebagai seorang perawat, kita diharapkan untuk memiliki rentang perhatian yang luas terhadap berbagai respon yang dilakukan oleh klien, baik pada saat klien sakit maupun sehat.Respon-respon tersebut merupakan reaksi terhadap masalah kesehatan dan proses kehidupan yang dialami klien. Sehingga, diharapkan perawat mampu menangkap dan berfikir kritis dalam merespon perilaku tersebut.

Masalah kesehatan mengacu pada kepada respon klien terhadap kondisi sehat-sakit, sedangkan proses kehidupan mengacu kepada respon klien terhadap kondisi yang terjadi selama rentang kehidupannya dimulai dari fase pembuahan hingga menjelang ajal dan meninggal yang membutuhkan diagnosis keperawatan dan dapat diatasi atau diubah dengan intervensi keperawatan.

Salah satu cara agar perawat dapat membuat dokumentasi yang baik dapat dengan cara manajemen rumah sakit memonitoring dan mengevaluasi baik secara kualitatif maupun kuantitatif penyusunan diagnosa keperawatan, serta menetapkan standar diagnosa keperawatan yang terkini.

\section{PEMBAHASAN}

Profesi perawat menggunakan proses keperawatan (nursing process) sebagai kerangka pikir dan kerangka kerja dalam merawat pasien. Keperawatan sebagai proses terdiri dari assessment (pengkajian), diagnosis (penetapan diagnosa), planning outcomes (perencanaan hasil), planning intervention (perencanaan intervensi), implementation (implementasi) dan evaluation (evaluasi) (Wilkinson, J., M 2007). Pada prakteknya kegiatan proses keperawatan di atas tidaklah selalu berurutan tetapi bisa dikerjakan pada waktu bersamaan/tumpang tindih (overlapping). Pengalaman menunjukkan bahwa sering sekali perawat kesulitan dalam menentukan diagnosa karena pengkajian yang dilakukan oleh perawat tidak mempunyai urutan yang efektif dan terstruktur (Nurjannah, I. 2012.). Akuntabilitas perawat sebagai profesi diantaranya adalah kompetensinya dalam mendokumentasikan diagnosa keperawatan sesuai standar diagnosa keperawatan Indonesia (SDKI). Kompetensi ini dibutuhkan dalam rangka menjamin kualitas asuhan keperawatan kepada masyarakat

Diagnosis keperawatan merupakan penilaian klinis terhadap pengalaman/respon individu, keluarga, atau komunitas pada masalah kesehatan/risiko masalah kesehatan atau pada proses kehidupan. Diagnosis keperawatan merupakan bagian vital dalam menentukan 
asuhan keperawatan yang sesuai untuk membantu klien mencapai kesehatan yang optimal. Perawatan yang profesional dicerminkan dalam pendokumentasian yang profesional, yang membuktikan tentang apa yang dilakukan oleh perawat dan secara efektif menggambarkan status dan kemajuan klien. Informasi yang menggambarkan masalah klien atau diagnosis keperawatan kemudian mengarah pada pemberian asuhan keperawatan untuk memilih suatu rencana perawatan yang sesuai dengan terapi keperawatan (Potter \& Perry; 2009).

Diagnosis keperawatan memiliki 2 kompinen utama, yaitu Masalah (Problem) atau Label Diagnosis dan Indikator Diagnostik.

1. Masalah (Problem)

Masalah merupakan label diagnosis keperawatan yang menggambarkan inti dari respon klien terhadap kondisi kesehatan atau proses kehidupannya.

Label diagnosis ini terdiri dari Deskriptor atau penjelas dan Fokus Diagnostik.

Deskriptor merupakan pernyataan yang menjelaskan bagaimana suatu fokus diagnosis terjadi. Beberapa deskriptor yang digunakan dalam diagnosis keperawatan diuraikan melalui gambar dibawah ini.

2. Indikator Diagnostik

Indikator diagnostik terdiri dari penyebab, tanda/gejala, dan faktor resiko dengan uraian sebagai berikut.

a. Penyebab (Etiology)

Merupakan faktor-faktor yang mempengaruhi perubahan status kesehatan. Etiologi ini dapat mencakup 4 kategori, yaitu;

- Fisiologis, Biologis atau Psikologis,

- Efek Terapi/Tindakan,

- Situasional (lingkungan atau personal)

- Maturasional

b. Tanda (Sign) dan Gejala (Symptom)

Tanda merupakan data objektif yang diperoleh dari hasil pemeriksaan fisik, pemeriksaan laboratorium dan prosedur diagnostik.

Sedangkan gejala merupakan data subjektif yang diperoleh dari hasil anamnesis atau pengkajian.

Tanda/gejala ini dikelompokan menjadi 2 kategori, yaitu:

- Tanda/Gejala Mayor: Ditemukan sekitar 80\% - 100\% untuk validasi diagnosis.

- Tanda/Gejala Minor: Tidak harus ditemukan, namun jika ditemukan dapat mendukung penegakan diagnosis. 


\section{c. Faktor Resiko (Risk Factor)}

Merupakan kondisi atau situasi yang dapat meningkatkan kerentanan klien dalam mengalami masalah kesehatan atau proses kehidupannya. Indikator diagnosis ini akan berbeda-beda pada masing-masing macam jenis diagnosis.

- Pada diagnosis aktual, indikator diagnostiknya terdiri dari penyebab dan tanda/gejala.

- Pada diagnosis resiko, tidak memiliki penyebab dan tanda/gejala, melainkan hanya faktor resiko saja.

- Pada diagnosis promosi kesehatan, hanya memiliki tanda/gejala yang menunjukan kesiapan klien untuk mencapai kondisi yang lebih optimal.

Proses penegakan diagnosis (diagnostic process) adalah suatu proses yang sistematis yang terdiri dari 3 tahap yaitu, analisis data, identifikasi masalah dan perumusan diagnosis. Untuk perawat profesional yang telah berpengalaman, proses ini dapat dilakukan secara simultan. Namun untuk perawat yang belum memiliki pengalaman yang memadai, setidaknya diperlukan latihan dan pembiasaan untuk melakukan proses penegakan diagnosis secara sistematis.

Proses penegakan diagnosis keperawatan diuraikan sebagai berikut;

1. Analisis DataTahap pertama dalam proses penegakan diagnosis keperawatan adalah Analisis data yang dilakukan dengan tahapan sebagai berikut ini.

a. Bandingkan data dengan nilai normal/rujukan

b. Kelompokkan data

\section{Identifikasi Masalah}

Setelah data dianalisis, perawat dan klien bersama-sama mengidentifikasi masalah, mana masalah yang aktual, resiko dan /atau promosi kesehatan.

\section{Perumusan Diagnosis Keperawatan}

Perumusan atau penulisan diagnosis disesuaikan dengan jenis diagnosis keperawatannya.

Persatuan Perawat Nasional Indonesia (PPNI) merupakan Organisasi Profesi (OP) yang diakui dalam UU Keperawatan memiliki bertanggung jawab dalam meningkatkan dan mengembangkan pengetahuan dan keterampilan, martabat, dan etika profesi perawat di Indonesia. Dalam mencapai tujuan dan menjalankan fungsi tersebut, salah satunya PPNI berkewajiban untuk menyusun standar-standar yang meliputi standar kompetensi, standar asuhan keperawatan, dan standar kinerja profesional. Standar asuhan keperawatan dibutuhkan Standar Diagnosis Keperawatan, oleh karena PPNI menerbitkan Standar Diagnosis Keperawatan Indonesia (SDKI). Diagnosis keperawatan telah diterapkan di berbagai rumah 
sakit dan fasilitas kesehatan lainnya, namun pengetahuan perawat terkait indikator-indikator diagnostik untuk penegakan diagnosis masih perlu ditingkatkan agar penegakan dapat dilakukan secara tepat dan terstandarisasi, serta proses penegakan diagnosisi tidak dianggap sulit. Tanpa terminologi dan indikator yang terstandarisasi, penegakan diagnosis keperawatan menjadi tidak seragam, tidak akurat dan ambigu sehingga menyebabkan ketidaktepatan pengambilan keputusan dan ketidaksesuaian asuhan keperawatan yang diberikan kepada klien.

Sesuai pasal 13 UU No. 44 Tahun 2009 tentang RS, setiap tenaga kesehatan yang bekerja di Rumah Sakit (RS) harus bekerja sesuai dengan standar profesi, standar pelayanan RS, standar prosedur operasional yang berlaku, etika profesi, menghormati hak pasien dan mengutamakan keselamatan pasien. Pasal 30 UU No. 38 Tahun 2014 tentang Keperawatan Dalam menjalankan tugas sebagai pemberi asuhan keperawatan, perawat berwenang untuk menegakkan diagnosis keperawatan. Perawat harus sebagai 'Penegak Diagnosis' keperawatan yang sudah terstandar dan ditetapkan oleh organisasi profesi PPNI dan disahkan oleh menteri, yaitu Standar Diagnosis Keperawatan Indonesia (SDKI).

Hal yang dimaksud dengan standar profesi adalah batasan kemampuan (capacity) meliputi pengetahuan (knowledge), keterampilan (skill), dan sikap professional (professional attitude) yang minimal harus dikuasai oleh seorang individu untuk dapat melakukan kegiatan profesionalnya pada masyarakat secara mandiri yang dibuat oleh organisasi profesi. SDKI merupakan standar mutu proses bagi pelayanan keperawatan di rumah sakit khususnya yang akan melandasi standar asuhan keperawatan nantinya. SDKI harus memenuhi beberapa persyaratan antara lain tidak lepas dari standar diagnosa keperawatan internasional; memiliki evidence based yang kuat, merupakan hasil survei dari RS, puskesmas, kementerian kesehatan, riset dan pendidikan keperawatan di Indonesia. Adopsi dari luar diperbolehkan jika melewati uji kelayakan yang sesuai dengan kondisi negara kita, disempurnakan menjadi Standar Asuhan Keperawatan dan tidak terpisah dengan komponen Asuhan Keperawatan yang lainnya.

Panduan penulisan diagnosis keperawatan NOC, NIC (2011). North American Nursing Diagnosis Association (NANDA) merupakan salah satu sistem klasifikasi keperawatan yang terstandarisasi, sebagai sistem klasifikasi untuk proses analisis dan penyajian akhir data pengkajian dan identifikasi masalah pasien. Penggunaan sistem klasifikasi akan memudahkan perencanaan dan intervensi untuk membantu pasien mengatasi masalah penyakitnya dan memperoleh kembali status kesehatan dan aktivitasnya yang normal. Sistem klasifikasi yang juga telah dikembangkan dalam keperawatan adalah Nursing 
Intervention Classification (NIC) dan Nursing Outcome Classification (NOC) (Aprisunadi, 2011).

Menurut NANDA, diagnosis keperawatan adalah keputusan klinik mengenai respons individu (klien dan masyarakat) tentang masalah kesehatan aktual atau potensial sebagai dasar seleksi intervensi keperawatan untuk mencapai tujuan asuhan keperawatan sesuai dengan kewenangan perawat (Nursalam, 2008). NOC merupakan salah satu bahasa standar yang diakui oleh America Nursing Association (ANA). Sebagai bahasa yang diakui memenuhi standar pedoman yang ditetapkan oleh bahasa Informasi Keperawatan ANA dan Data Set Evaluasi Pusat (NIDSEC) untuk vendor sistem informasi.

NOC termasuk dalam Perpustakaan Nasional Metathesaurus Kedokteran Ahli Bahasa Medis Bersatu dan Indeks Kumulatif untuk Sastra Keperawatan (CINAHL) dan telah disetujui untuk digunakan oleh Kesehatan Tingkat 7 Terminologi (HL7) (Moorhead, Johnson, Maas, \& Swanson, 2013). Nursing Intervention Classification (NIC) merupakan standar intervensi yang komprehensif dan berdasarkan riset.

NIC sangat berguna untuk dokumentasi, komunikasi pada banyak setting, integrasi pada sistem dan setting yang berbeda, riset yang efektif, pengukuran produktifitas dan evaluasi kompetensi, pembiayaan dan rancangan kurikulum (Yuniarti, 2005). NIC menggunakan bahasa yang dapat dihubungkan kepada North American Nursing Diagnosis Association (NANDA) dan Nursing Outcome Classification (NOC). Menurut pendapat peneliti intervensi yang diberikan berupa pelatihan Stnadard Nursing Language berbasis NANDA, NOC dan NIC dapat meningkatkan kemampuan perawat dalam pembuatan standar asuhan keperawatan serta pengetahuan perawat. Semakin tinggi tingkat pengetahuan perawat, maka semakin mempengaruhi cara pandang perawat, sehingga dapat mempengaruhi perilakunya yang akan berdampak terhadap kemampuannya dalam pengisian dokumentasi keperawatan yang berkualitas.

\section{PENUTUP}

\section{Kesimpulan}

Diagnosis keperawatan memiliki 2 kompinen utama, yaitu Masalah (Problem) atau Label Diagnosis dan Indikator Diagnostik. Proses penegakan diagnosis (diagnostic process) adalah suatu proses yang sistematis yang terdiri dari 3 tahap yaitu, analisis data, identifikasi masalah dan perumusan diagnosis. Untuk perawat profesional yang telah berpengalaman, proses ini dapat dilakukan secara simultan. Namun untuk perawat yang belum memiliki 
pengalaman yang memadai, setidaknya diperlukan latihan dan pembiasaan untuk melakukan proses penegakan diagnosis secara sistematis. Menurut pendapat peneliti intervensi yang diberikan berupa pelatihan Stnadard Nursing Language berbasis NANDA, NOC dan NIC dapat meningkatkan kemampuan perawat dalam pembuatan standar asuhan keperawatan serta pengetahuan perawat. Semakin tinggi tingkat pengetahuan perawat, maka semakin mempengaruhi cara pandang perawat, sehingga dapat mempengaruhi perilakunya yang akan berdampak terhadap kemampuannya dalam pengisian dokumentasi keperawatan yang berkualitas.

\section{Saran}

Untuk menciptakan perawat professional dalam melakukan asuhan keperawatan khususnya dalam pembuatan diagnosa keperawatan, perawat perlu mendapat pelatihan Stnadard Nursing Language berbasis NANDA, NOC dan NIC untuk meningkatkan pengetahuan dan skil perawat.

\section{Daftar Pustaka}

Apriyan, H. (2015). Identifikasi Diagnosis Keperawatan Pada Pasien Di Ruang Paru Sebuah Rumah Sakit, Jurnal Keperawatan, 11(1), 107-108.

Atmanto, A. P., Aggorowati., \& Muhammad, R. (2020). Efektifitas Pedoman Pendokumentasian Diagnosa Dan Intervensi Keperawatan Berbasis Android Terhadap Peningkatan Mutu Dokumentasi Keperawatan Di Ruang Rawat Inap. Jurnal Keperawatan dan Kesehatan Masyarakat, 9(1), 83-85.

Cikwanto., \& Nupiyant. (2018). Pengembangan Instrumen Penegakan Diagnosis Keperawatan Pada Pasien Congestive Heart Failure (CHF) Berbasis Standar Diagnosis Keperawatan Indonesia (SDKI). Jurnal Keperawatan 'Aisyiyah, 5(1), 51-61.

Fatie, M., \& Roberth, Z. F. (2018). Hubungan Tingkat Pendidikan Perawat Dengan Penerapan Kompetensi Pendokumentasian Proses Keperawatan. Jurnal Keperawatan Tropis Papua,1(1), 19-24.

Hendriana, Y., \& Aria, P. (2019). Standar nursing language berbasis NANDA, NOC, dan NIC terhadap kualitas pengisian dokumentasi keperawatan. Jurnal Penelitian dan Pemikiran Ilmiah Keperawatan, 5(2), 26-34

Koerniawan, D., Novita, E., \& Srimiyati. (2020). Aplikasi Standar Proses keperawatan: Diagnosis, Outcome, Dan Intervensi Pada Asuhan Keperawatan. Jurnal Keperawatan Silampari, 3(2), 740-749.

Kusnadi, E. (2017). Analisis Kelengkapan Dokumentasi Keperawatan di Ruang Rawat Inap Non Intensive Rumah Sakit X. Jurnal Bidang IImu Kesehatan, 9(1), 553-560.

Ramdani, H. T., \& Sulastini. (2019). Efektivitas Nursing Diagnostic Mobile Terhadap Pendokumentasian Diagnosa Keperawatan Pada Mahasiswa Yang Melaksanakan Praktik Belajar Lapangan. Jurnal Keperawatan Dirgahayu, 1(2), 52-53.

Simamora, R. H. (2019). Socialization of Information Technology Utilization and Knowledge of Information System Effectiveness at Hospital Nurses in Medan, North Sumatra. Editorial Preface From the Desk of Managing Editor..., 10(9). 
Simamora, R. H., Bukit, E., Purba, J. M., \& Siahaan, J. (2017). Penguatan kinerja perawat dalam pemberian asuhan keperawatan melalui pelatihan ronde keperawatan di rumah sakit royal prima medan. Jurnal pengabdian kepada masyarakat, 23(2), 300-304.

Supratti., \& Ashriady. (2016). Pendokumentasian Standar Asuhan Keperawatan Di Rumah Sakit Umum Daerah Mamuju, Indonesia. Jurnal Kesehatan MANARANG, 2(1), 47-51.

Suryono., \& Christianto. N. (2020). Kompetensi Perawat Mendokumentasikan Diagnosis Keperawatan Berdasarkan Standar Diagnosis Keperawatan Indonesia (SDKI). Jurnal ILKES (Jurnal IImu Kesehatan), 11(1), 233-234. 